\title{
The Electrical State of the Upper Atmosphere.
}

THE meeting of the Royal Society on March 4 was devoted to a general discussion on the subject of "The Electrical State of the Upper Atmosphere," at which a number of prominent physicists interested in this subject had been invited to take part. The large attendance at the meeting showed the importance of the subject in the scientific world at the present time; and it was evident that a very useful purpose was being served in directing the attention of the meteorological and atmospheric physicists to the insistent demands made by modern wireless research for an upper ionised stratum in the atmosphere which is capable of deflecting wireless waves and returning them to the earth's surface.

In opening the discussion, the president of the Royal Society, Sir Ernest Rutherford, outlined the three possible methods of investigating the upper atmosphere. Above the limits of direct observation, the pressure and temperature are to some extent calculable, while observations on meteors provide experimental information. The highly penetrating radiation recently investigated by Millikan was found to increase in intensity upwards from the earth's surface, and the suggestion was made that this radiation might possibly originate in thunderstorms. It was pointed out that in order to obtain a permanently ionised layer it is not necessary to assume a very strong ionising agent ; since, owing to the slow rate of recombination at the higher levels, a small rate of production of ions may result in a very large permanent ionisation.

With the aid of a carefully prepared chart, Prof. Sydney Chapman, of the Imperial College of Science and Technology, then summarised our present knowledge of the physical constants of the atmosphere. By means of self-registering instruments carried in sounding balloons, direct observations have been made at heights up to $30 \mathrm{~km}$. The absolute temperature of the atmosphere decreases from $285^{\circ}$ at the earth's surface to $220^{\circ}$ at a height of ro $\mathrm{km}$., which is the upper limit of the troposphere. Above this the temperature remains constant up to a height of $60 \mathrm{~km}$., where it begins to increase again to a value approaching $300^{\circ}$ for a height of $100 \mathrm{~km}$. At this height the pressure and density of the air have values which are about $10^{-5}$ of those at the ground level, while the mean free path of the molecules increases from $10^{-5}$ at the earth's surface to $3 \mathrm{~cm}$. at $100 \mathrm{~km}$. height. The gaseous constituents of the atmosphere are thoroughly mixed as the result of winds in the lower regions, but they become separated at the higher levels with nitrogen as the main constituent. The existence of aurora at heights of from $90 \mathrm{~km}$. upwards appears to require the lifting of gases from the lower regions. Attention was further directed to the comparatively high conductivity which the ionised layer is required to possess in order to explain the phenomena of terrestrial magnetism.

Mr. C. T. R. Wilson referred to recently published data on thunderstorm distribution, from which it has been deduced that about $\mathrm{x} 800$ thunderstorms are in continual progress over the earth's surface, accompanied by lightning flashes at an average rate of one hundred per second. Combining these results with the experimental measurements of the quantity of electricity in each lightning flash, it was shown that these thunderstorms represent an energy supply having the enormous value of $10^{\mathbf{1 2}}$ watts, which, however, is only $10^{-\mathbf{4}}$ of the energy received by the earth from the sun in the form of heat. It was suggested that electrons moving in electric fields with strengths of the order of 10,000 volts per $\mathrm{cm}$. in the neighbourhood of lightning flashes, may be responsible for a very penetrating form of radiation in the atmosphere. In a later portion of the discussion Mr. Dobson described results obtained in observations on the disappearance of meteors and showed that this leads to increased values for the temperature and pressure of the atmosphere at heights of the order of $100 \mathrm{~km}$.

The radio aspect of the discussion was opened by Sir Henry Jackson, who emphasised the long-felt need of an adequate explanation of long-distance wireless signalling, of the variations in signal intensity, and of the more recently observed variations in apparent directions of arrival of wireless waves at a receiving station. He stated that during the last few years an enormous amount of experimental data on these points has been obtained by a group of investigators associated with the Radio Research Board and that the experimental facts are now well established. All this work indicates the necessity for a layer in the upper regions of the earth's atmosphere which is capable of deflecting waves reaching it in such a manner as to return them to the earth's surface. A brief account was also given of some recent experiments carried out on a wave-length of $\mathrm{I} 2$ metres in which a ship transmitter was employed. As the ship proceeded away from the receiving station the signals disappeared for a range of transmission of about roo miles. This was presumably due to the high attenuation of such waves in travelling over the earth's surface, although accurate knowledge on this point is still lacking. As the ship proceeded on its course no signals were received until the distance was increased to rroo miles, beyond which the signals again disappeared. At 3000 miles and again at 6000 miles the signals were very clearly heard, although they were inaudible at intermediate ranges. Such results as these demand for their explanation an ionised layer which will permit the passage of wireless waves with a very small attenuation and will arrange for waves to be returned to the earth at certain places only.

Prof. E. V. Appleton indicated the desirability of investigating the wireless phenomena at comparatively short distances, and then described two sets of experiments, carried out with the assistance of Mr. M. A. F. Barnett, which provide proof of the reception of downcoming wireless waves at the earth's surface. The first of these demonstrated the interference between two sets of waves from the same transmitting station, one set having travelled along the earth's surface and the other set via the upper regions of the earth's atmosphere. The second experiment was based on the fact that, for an electromagnetic wave arriving at the surface of a conductor, the resultant horizontal

$$
\text { NO. 294I, VOL. II7] }
$$


magnetic force is greater than that of the vertical electric force, and by measuring the ratio of these forces the angle of incidence of the waves can be calculated. Attention was directed to the importance of the earth's magnetic field on the operation of the ionised layer, and also to the fact that, from observations on very short wave-lengths, information is obtainable as to the density of electrons required in this layer.

The next contribution to the discussion was made by Dr. R. L. Smith-Rose and Mr. R. H. Barfield, who gave a brief account of some of their recent experimental measurements on wireless waves received from the upper atmosphere. By means of careful measurements of the directions of both the electric and magnetic forces at the earth's surface due to wireless waves from a distant transmitting station, it was shown that, at times in the neighbourhood of sunset and in the hours of darkness, some of the received waves were travelling in a downward direction, evidently the result of deflexion from the upper atmosphere. Several methods of measuring the angle of incidence and relative intensities of such waves have been developed and give consistent results. In an example given in the paper, the angles of incidence varied from $I 3^{\circ}$ to $34^{\circ}$, and the latter value is shown to correspond to a height of deflecting layer of about $88 \mathrm{~km}$., which is in good agreement with the results of other investi- gators. The intensity of such downcoming waves is of the same order as the direct wave along the earth's surface which is received simultaneously, and the combination of the two sets of waves is responsible for the variations in signal intensity in the readings of a direction-finder which were observed during the experiments. The need for further investigation and the lines of proposed future experiments were mentioned by these speakers.

In concluding the radio side of the discussion, Prof. W. H. Eccles reminded the audience that the observed effects might vary very much over the enormous range of wave-lengths which is now being used in practical wireless communications. The diffraction of the waves around the curvature of the earth would be appreciably different with wave-lengths of, say, 20 and 20,000 metres, and it is also possible that the shorter of these waves may be returned to earth at a comparatively low height, about $30 \mathrm{~km}$., in the atmosphere. The speaker directed attention to some lacunæ in the Larmor theory of the propagation of waves, and emphasised the need of further experiments directed towards the elucidation of some points which are at present somewhat obscure.

Among the speakers who took part in the later portion of the discussion, Dr. G. C. Simpson stated that Britain now leads the world in the matter of knowledge and research on the science of the upper atmosphere.

\section{Transatlantic Radio Telephony.}

$\mathrm{O}^{\mathrm{N}}$ S Sunday, March 7, the General Post Office gave representatives of the Press an opportunity of taking part in the engineering tests, made in the ordinary course, by the technical staffs of the General Post Office and the American Telegraph and Telephone Company. Mr. Shaughnessy, the engineer in charge, gave an interesting résumé of what has already been done. He also described the route that is travelled by the voice signals and detailed some of the many difficulties that will have to be overcome before twoway telephony between London and New York can be established on a commercial basis. So far back as I9I4 the engineers of the Bell system in the United States succeeded in establishing one-way communication between Arlington and Panama, San Francisco, Honolulu and Paris successively. Three years ago similar experiments between London and New York proved that it was highly probable that a limited two-way service could be established.

In England, the circuit ends at the London Trunk Exchange of the British Post Office. In the United States it is terminated at the headquarters of the American Telegraph and Telephone Company at 24 Walker Street, New York City. In speaking from London, the signals are carried by underground telephone wires through two repeater stations direct into the microphone of the Post Office Radio sending station at Rugby, where the aerial used is carried by five lattice masts each $820 \mathrm{ft}$. high and a quarter of a mile apart. The radio signals then go a distance of 2900 miles to the receiving station at Houlton, Maine. From there they traverse a distance of 600 miles through two repeater stations to New York.
In transmitting from New York the speech is carried a distance of 70 miles to the sending station of the Radio Corporation at Rock Point, Long Island. From there it is transmitted by radio a distance of 3300 miles to the Post Office receiving station at Wroughton, near Swindon. From this point it is carried over a telephone circuit to London, a distance of 90 miles.

The wave-length utilised in England is 5770 metres and in the United States 5260 metres. The power used at each end is about 200 kilowatts, but owing to improvements in the method of radio transmission adopted, the ordinary broadcasting telephony station would have to employ about double this power to attain the same efficiency.

Arrangements were made by means of which some twenty press representatives in London had two-way conversations with their American confrères. These conversations could be overheard by all those present. The speech was remarkably clear, being quite equal to that heard in ordinary telephony. It was stated that the atmospheric conditions were favourable. Very little disturbance was produced by Morse or atmospherics. The difference between the voices of the speakers was clearly recognisable. This was the first occasion on which group conversations by the public were held between London and New York.

The Post Office engineers are to be congratulated on the many difficulties they have overcome, particularly in balancing the land telegraph lines in order to get two-way transmission. We are still, however, a long way from commercial telephony across the Atlantic. Doubtless it will come in the future. We wish the engineers every success in their strenuous endeavours.

$$
\text { NO. } 294 \text { I, VOL. I I } 7]
$$

